\title{
HUBUNGAN ANTARA KECERDASAN INTELEKTUAL (IQ) DENGAN PRESTASI BELAJAR SISWA PADA MATA PELAJARAN PENDIDIKAN KEWARGANEGARAAN
}

\author{
(Studi Korelasi Pada Pembelajaran Pendidikan Kewarganegaraan Kelas VII \\ MTs Negeri 1 Serang)
}

\author{
Aliza Alfionita1), Ujang Jamaludin ${ }^{2)}$, Dinar Sugiana Fitrayadi ${ }^{3)}$ \\ Program Studi Pendidikan Pancasila dan Kewarganegaraan, Fakultas Keguruan dan Ilmu \\ Pendidikan, Universitas Sultan Ageng Tirtayasa \\ alizaalfionita@gmail.com ${ }^{1)}$,dinar.sugiana@untirta.ac.id ${ }^{2)}$
}

\begin{abstract}
This study aims to find out the relationship between Intellectual Intelligence and Student Learning Citizenship Education Lessons. The research method of this research is a quantitative correlation approach. Samples were taken by Proposal Random Sampling technique, which was 72 samples. The instruments used in this study were Intelligence Tests and used Achievement Tests and observations as supporting data. While the data analysis used Simple Linear Regression with intellectual intelligence $(x)$ as a predictor and learning achievement of Citizenship Education (Y). by komasiasi obtained the following correlation coefficient of 0.716 means $(0,513 x$ $100 \%)=51.3 \%$. Learning Achievement Citizenship Education is influenced by intellectual intelligence while the remaining $48.7 \%$ is determined by other variables which are not examined in this study. Based on the results of the study, it can be concluded that Intellectual Intelligence has a Significant Relationship with Student Achievement in Citizenship Education.
\end{abstract}

Keywords: Intellectual Intelligence ( IQ ) and Learning Achievement.

\section{PENDAHULUAN}

Pendidikan merupakan sebuah usaha merupakan sarana dalam rangka ataupun cara yang sangat penting dilakukan pencapaian tujuan pendidikan tersebut. guna meningkatkan kulaitas manusia. Undang Undang R.I No. 20 Tahun 2003 Pendidikan adalah suatu usaha atau tentang Sistem Pendidikan Nasional Pasal 1 kegiatan yang dijalankan dengan sengaja, ayat (2) dinyatakan bahwa : "Pendidikan teratur dan berencana dengan maksud merubah atau mengembangkan perilaku yang diinginkan. Untuk itu dalam pendidikan terdapat kegiatan pembelajaran sebagai pokoknya. Ada dua komponen utama yang berperan dalam kegiatan belajar mengajar yaitu guru dan siswa, sekolah sebagai lembaga formal yang adalah usaha sadar dan terencana untuk mewujudkan suasana belajar dan proses pembelajaran agar peserta didik secara aktif mengembangkan potensi dirinya untuk memiliki kekuatan spiritual keagamaan, pengendalian diri, kepribadian, kecerdasan, akhlak mulia, serta keterampilan yang diperlukan dirinya, masyarakat, bangsa dan 
negara". Masyarakat umum mengenal intelektual sebagai istilah-istilah yang menggambarkan kecerdasan, kepintaran, ataupun untuk memecahkan problem yang dihadapi menurut Azwar, 1996. Sedangkan Kecerdasan Intelektual adalah dilihat dari intelektualnya, kita dapat mengatakan cerdas, berakal dan berfikiran jernih berdasarkan ilmu pengetahuan, yang mempunyai kecerdasan tinggi terutama yang menyangkut pemikiran dan pemahaman (Retno Ayu Pratiwi. 2011:23). Terkait dengan hal ini, Kecerdasan Intelektual adalah dapat berpengaruh terhadap prestasi belajar siswa. Dimana, anak - anak yang berkecerdasan intelektual tinggi akan mampu dengan baik mengerjakan tes terstandarisasi dan mengikuti pendidikan lebih lama. Dengan demikian kecerdasan berpengaruh terhadap prestasi belajar (Ormrod, Jeanne.Ellis. 2008:218). "Heidenrich menyatakan bahwa: "intelligence refers to the ability to learn and to utilize what has been learned in adjusting to unfamiliar situations, or in the solving of problems". Maksud dari pernyataan tersebut adalah inteligensi menyangkut kemampuan untuk belajar dan menggunakan apa yang telah dipelajari dalam usaha penyesuaian terhadap situasisituasi yang belum dikenal, atau dalam pemecahan masalah - masalah. Menurut dalyono dalam psikologi pendidikan.
2009:184). Pengembangan kecerdasan intelektual siswa merupakan salah satu kegiatan untuk meningkatkan kemampuan dalam pembelajaran dan dapat dilaksanakan dalam proses belajar mengajar. Sedangkan pengertian belajar adalah merupakan suatu proses yang kompleks karena dapat dipengaruhi oleh banyak hal yaitu pembawaan, gizi, kematengan, pembentukan, kebebasan psikologis, minat dan pembawaan yang khas dan stabilitas intelegensi dan IQ.

\section{Perkembangan Siswa/ Remaja.}

Usia remaja adalah usia yangsangat krusial, hal ini diakubatkan oleh perkembangan pola pikir yang masih belub stabil, dalam hal ini salah satu yang termasuk usia remaja adalah salah satunya anak yang duduk di bangku sekolah menengah pertama. Remaja sebagai periode tertentu dari kehidupan manusia merupakan suatu konsep yang relative baru dalam kajian psikologi. menurut Abin Syamsuddin Makmun, (2004:78-79). Ciri-ciri Remaja Menurut Hurlock ( dalam Marliani, 2016:65) Ada delapan ciri-ciri yang melekat pada masa remaja, yaitu sebagai berikut.
a. Periode penting
b. Periode peralihan
c. Masa perubahan
d. Usia bermasalah 


\section{Kecerdasan Intelektual}

Kecerdasan Intelektual adalah kecerdasan intelektual berpengaruh terhadap prestasi belajar siswa. Dimana, anak - anak yang berkecerdasan intelektual tinggi akan mampu dengan baik mengerjakan tes terstandarisasi dan mengikuti pendidikan lebih lama. Dengan demikian kecerdasan berpengaruh terhadap prestasi belajar (ormrod, Jeanne.Ellis. 2008: 218). Kecerdasan intelektual adalah kemampuan yang dibutuhkan untuk melakukan berbagai aktifitas mental berfikir, menalar dan memecahkan masalah ( Robin dan Judhe dalam Dwijayanti, 2009:57). Kecerdasan Intelektual adalah sebagai kemampuan untuk belajar dari pengalaman, berfikir menggunakan proses-proses metakognitif, dan kemampuan untuk beradaptasi dengan lingkungan sekitar menurut ( Sternberg, 2008:121 ).

\section{Faktor yang mempengaruhi}

\section{Kecerdasan Intelektual}

Menurut (Ngalim Purwanto,2013:5556), kecerdasan intelektual manusia dipengaruhi oleh beberapa factor yaitu:
a. Faktor Pembawaan
b. Faktor Gizi
c. Faktor Kematangan
d. Faktor Pembentukan

\section{e. Faktor Kebebasan Psikologi}

\section{Prestasi Belajar}

Salah satu tolak ukur berhasil atau tidaknya proses pembelajaran bisa dilihat dari prestasi belajar yang diraih peserta didik selama di sekoah. (Menurut Winkel dalam Hamdani. 2011: 138 ). Prestasi Belajar adalah Prestasi belajar merupakan hasil dari sebagian faktor yang mempengaruhi proses belajar secara keseluruhan (Syah, 2008: 141). Bahwa prestasi belajar adalah pencapaian atau kecakapan yang dinampakkan dalam keahlian atau kumpulan pengetahuan (Hetika,2008: 23).

\section{Faktor-faktor yang mempengaruhi Prestasi Belajar:}

Faktor yang mempengaruhi prestasi belajar menurut Sumandi Suryabrata (2010:23):

a. Faktor-faktor yang berasal dari luar diri anak didik di bagi menjadi dua, yaitu:

1. Faktor-faktor Sosial

2. Faktor-faktor Non Sosial

b. Faktor-faktor yang berasal dari dalam diri anak didik di bagi menjadi dua yaitu:

1. Faktor-faktor Fisiologis

2. Faktor-faktor Psikologis 


\section{Indikator Prestasi Belajar}

Indikator Prestasi Belajar anak sebagai Objek penilaian dapat diberikan dalam beberapa kategori, anatara lain keterampilan, sikapa dan Pengetahuan. Kategori yang banyak digunakan dibagi menjadi tiga yaitu: Kognitif, Afektif dan Psikomotorik. Ranah kognitif berkenaan dengan hasil belajar Intelektual yang terdiri dari enam Aspek mengingat, pemahaman, Penerapan, analisis, sintesis dan mencipta.

\section{Pendidikan Kewarganegaraan}

Pendidikan Kewarganegaraan adalah upaya sadar dan terencana untuk mencerdaskan kehidupan bangsa bagi warganegara dengan menumbuhkan jati diri dan moral bangsa sebagai landasan pelaksanaan hak dan kewajiban dalam bela Negara, demi kelangsungan kehidupan dan keyakinan bangsa dan Negara ( Damardi, 2010:3).

Pendidikan Kewarganegaraan dapat diartikan sebagai penyiapan generasi muda dalam hal ini pelajar (siswa) untuk menjadi seorang warga negara yang mempunyai pengetahuan, kecakapan dan nilai-nilai yang di perlukan untuk bisa berpartisipasi aktif dalam masyarakatnya (Samsuri, 2011: 28). Pendidikan Kewarganegaraan adalah seleksi, adaptasi dari lintas disiplin ilmu- ilmu sosial, ilmu kewarganegaraan, humaniora, teknologi, agama, kegiatan dasar manusia yang diorganisir dan disajikan secara psikologis dan ilmiah untuk ikut mencapai salah stu tujuan pendidikan ilmu pengetahuan social dan tujuan pendidikan Nasional. Somantri (dalam wuryan \& syaifullah, 2014: 76).

\section{Tujuan Mata Pelajaran Pendidikan Kewarganegaraan}

Mata Pelajaran Pendidikan

Kewarganegaraan menurut (Zubaedi. 2011:280) bertujuan agar siswa memiliki kemampuan sebagai berikut:

a. Berpikir secara kritis, rasional dan kreatif dalam menanggapi isu kewarganegaraan.

b. Berpartisipasi secara aktif dan bertanggung jawab, dan bertindak secara cerdas dalam kegiatan bermasyarakt, berbangsa, dan bernegara, serta anti korupsi.

c. Berkembang secara positif dan demokratis untuk membentuk diri berdasarkan karakter-karakter bangsabangsa lainnya.

d. Berinteraksi dengan bangsa-bangsa lain dalam percaturan dunia secara langsung atau tidak langsung dengan memanfaatkan teknologi dengan informasi dan komunikasi. 


\section{METODE PENELITIAN}

Penelitian ini merupakan Studi

Korelasional dimana Penelitian ini di MTs

Negeri 1 Serang. Penelitian ini dilakukan selama 3 Bulan, Mulai Bulan OktoberDesember. Populasi dalam penelitian tersebut adalah semua siswa Kelas VII Madrasah Aliyah Tsanawiyah Negeri 1 Serang. Tahun ajaran 2018/2019.yang berjumlah 278 siswa.

\section{Tabel 3.1}

\section{Populasi dan Sampel}

\begin{tabular}{cccc}
\hline Kelas & $\begin{array}{c}\text { Popula } \\
\text { si }\end{array}$ & Perhitungan & $\begin{array}{c}\text { Pembagian } \\
\text { sampel } \\
\text { (dibulatkan) }\end{array}$ \\
\hline VII A & 36 & $\frac{36}{278} \times 73=9.45$ & 9 \\
VII B & 36 & $\frac{36}{278} \times 73=9.45$ & 9 \\
VII C & 36 & $\frac{36}{278} \times 73=9.45$ & 9 \\
VII D & 34 & $\frac{34}{278} \times 73=8.92$ & 9 \\
VII E & 34 & $\frac{34}{278} \times 73=8.92$ & 9 \\
VII F & 34 & $\frac{34}{278} \times 73=8.92$ & 9 \\
VII G & 34 & $\frac{34}{278} \times 73=8.92$ & 9 \\
VII H & 34 & $\frac{34}{278} \times 73=8.92$ & 9 \\
Jumlah & 278 & & 72
\end{tabular}

Sampel dalam penelitian ini adalah MTs Negeri 1 Serang Kelas VII tahun pelajaran 2018/2019. Dari masing-masing kelas VII..

Pengambilan sampel dalam penelitian ini, dimana penelitian ini Populasi Berjumlah 278 siswa. Maka dapat diambil sampel berdasarkan rumusan sebanyak 10\%. Dari jumlah populasi. Sebagaimana sampel tersebut sebanyak 72 siswa. Sedangkan cara penarikan sampel dilakukan dengan Teknik Proposional dan Random Sampling. Sampel dalam penelitian ini mempergunakan perhitungan sampel yang dikembangkan oleh slovin dengan Rumus sebagai berikut:

$$
r=\frac{N}{1+N e^{2}}
$$

Suryani dan haryadi, (2015:194)

\section{Keterangan:}

$$
\begin{array}{ll}
\mathrm{N} & : \text { Sampel } \\
\mathrm{e} & : \text { Erros level (Tingkat } \\
\mathrm{N} & : \text { Kesalahan) }=10 \% \text { atau } \\
& \quad \text { sig : 0,1Populasi }
\end{array}
$$

Variabel kecerdasan intelektual (X) diambil dari hasil tes Intelegensi yang dilakukan oleh Biro Mentari Konsultan Psikologi, Tes ini menggunakan model The Standard progressive Matric (SPM) dan Tes Culture Fair Intellegance test (CIFIT II)

\section{Analisis Instrumen Penelitian}

Pengujian tingkat kesahihan (Validitas) dari setiap butir item dilakukan dengan menggunakan rumus Product Momment

$$
r x y \frac{n\left(\sum X Y\right)-\left(\sum X\right)\left(\sum Y\right)}{\left.\sqrt{\left(n \sum X^{2}\right.}-\left(\sum X\right)^{2}\right)\left(n \sum Y^{2}-\left(\sum Y\right)^{2}\right)}
$$

Riduwan, (2010:98) 
Keterangan:

$$
\begin{array}{ll}
\mathrm{r}_{\mathrm{xy}}= & \text { koefisien korelasi pearson product } \\
& \text { moment } \\
\mathrm{n} & =\text { jumlah siswa yang mengikuti tes } \\
\mathrm{x} & =\text { skor tiap item/ butir soal } \\
\mathrm{y} & =\text { skor soal }
\end{array}
$$

\section{Uji Reliabilitas}

reliabilitas juga merupakan syarat yang penting pada instrument yang reliable adalah instrument yang bila digunakan beberapa kali untuk mengukur objek yang sama akan menghasilkan data yang sama. Rumus yang digunakan untuk mencari koefisien reliabilitas tes bentuk Pilihan Ganda (PG) sebagai berikut:

\section{KR.20 ( Kuder Richardson)}

$$
r_{11}=\left(\frac{n}{n-1}\right)\left(1-\frac{\sum s_{i}^{2}}{s_{t}^{2}}\right)
$$

Sugiyono $(2017 ; 132)$

\section{Keterangan:}

$$
\begin{array}{ll}
\mathrm{r}_{11} & \text { : Koefisien Reliabilitas } \\
\mathrm{n} & \text { : Banyak Butir Soal } \\
\mathrm{S}_{\mathrm{i}}{ }^{2} & \text { : Jumlah Varians Skor setiap Butir } \\
& \text { Soal } \\
\mathrm{S}_{\mathrm{t}}{ }^{2} & \text { : Varians Skor Total } \\
\mathrm{X} & \text { : Skor tiap butir soal } \\
\mathrm{N} & \text { : Banyaknya siswa peserta tes }
\end{array}
$$

\section{Daya Pembeda}

Menurut Arikunto (2012:226) Daya Pembeda Soal adalah kemampuan sesuatu Soal untuk membedakan antara siswa yang berkemampuan tinggi dengan siswa yang berkemampuan rendah. Untuk mengetahui indeks daya pembeda soal bentuk Objektif menggunakan Rumus Sebagai Berikut :

$$
\mathrm{D}=\frac{\mathrm{B}_{\mathrm{A}}}{\mathrm{J}_{\mathrm{A}}}-\frac{\mathrm{B}_{\mathrm{B}}}{\mathrm{J}_{\mathrm{B}}}=\mathrm{P}_{\mathrm{A}}-\mathrm{P}_{\mathrm{B}}
$$

(Arikunto,2012:232)

\section{Keterangan :}

D : Daya Pembeda Soal

$\mathrm{J}_{\mathrm{A}} \quad$ : Banyaknya peserta kelompk atas

$\mathrm{J}_{\mathrm{B}}$ : Banyaknya peserta kelompk bawah

$\mathrm{B}_{\mathrm{A}}$ : Banyaknya peserta kelompok atas yang menjawab soal itu dengan benar

$\mathrm{B}_{\mathrm{B}}$ :Banyaknya Peserta Kelompok bawah yang menjawab soal itu dengan benar.

\section{Tingkat Kesukaran}

Menurut Arikunto (2012;222) soal yang baik adalah soal yang tidak terlalu mudah atau tidak terlalu sukar. Soal yang terlalu mudah tidak meranggsang siswa untuk mempertinggi usaha untuk memecahkannya. Sebaliknya keputusaasaan dan turunya semanagt beajar siswa dapat disebabkan oleh soal yang sukar. 


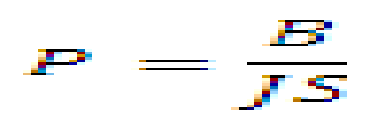

Keterangan :

P : Indeks Kesukaran

B :Banyaknya siswa yang menjawab soal dengan benar

JS : :jumlah Seluruh Siswa Peserta Tes

\section{TEKNIK ANALISIS DATA}

1. Deskripsi Data Skor IQ

Data Kuantitatif Skor IQ Mentah diolah dan Merubah ke dalam bentuk Nilai. Dalam penelitian ini dengan menentukan nilai yang diperoleh setiap peserta didik, dimana skor IQ dari Mentari Psikologi menentukan Rumus digunakan untuk menghitung nilai adalah sebagai berikut:

\section{Nilai $\frac{\text { Skor Yang diperoleh }}{\text { Skor Maksimum }} \times 100$}

(Arikunto, 2013;272)

2. Uji Prasyarat

\section{Uji Normalitas}

Uji Normalitas ini dimaksudkan untuk mengetahui apakah data memiliki distribusi normal atau tidak, peneliti ini menggunakan rumus Kolmogorovsmirnov, dengan rumus sebagai berikut:

$$
K D=1,36 \sqrt{\frac{n_{1}+n_{2}}{n_{1} X n_{2}}}
$$

Sugiyono, (2010: 159)
Keterangan :

$\mathrm{KD}=$ harga Kolmogorov- smirnov yang di cari

$\mathrm{N}_{1}=$ jumlah sampel yang diobservasikan / diperoleh

$\mathrm{n}_{2}=$ jumlah sampel yang diharapkan

\section{Uji Lineritas}

Uji lineritas dimaksudkan untuk mengetahui apakah pengaruh masingmasing variable bebas yang dijadikan predictor mempunyai hubungan linier atau tidak terhadap variable terikat. Rumus yang dapat di gunakan untuk uji linieritas adalah

$$
F_{\text {reg }}=\frac{R K_{r e g}}{R K_{\text {reg }}}
$$

Keterangan :

$\mathrm{F}_{\text {reg }}=$ harga bilangan $\mathrm{F}$ untuk garis regresi

$\mathrm{RK}_{\text {reg }}=$ rerata kuadrat garus regresi

$\mathrm{RK}_{\text {res }}=$ rerata kuadrat residu

\section{HIPOTESIS}

\section{Korelasi}

Untuk menguji korelasi antara dua variable (x dan y ) dapat menggunakan korelasi product Moment dengan Rumus Sebagai berikut:

$$
r_{x y}=\frac{N \sum X Y-\left(\sum X\right)\left(\sum Y\right)}{\sqrt{\left.N \sum X^{2}-\left(\sum X\right)^{2}\right)\left(N \sum Y^{2}-\left(\sum Y\right)^{2}\right)}}
$$

Sugiyono, (2014:184) 
Keterangan:

$\mathrm{r}_{\mathrm{xy}}$ : koefisien korelasi antara variable $\mathrm{x}$ dan y

$\mathrm{x} \quad$ : skor tiap item dari koresponden uji coba variable $\mathrm{x}$

y : skor tiap item dari koresponden uji coba variable y

$\mathrm{N}$ : jumlah subjek

\section{Regresi}

Digunakan untuk uji asosiatif, lebih ditujukan untuk mengestimasi/memprediksikan variabel bebas terhadap variabel terikat.

Regresi linear sederhana didasarkan pada hubungan fungsional ataupun kausal satu variabel independen dengan satu variabel dependen.

$$
Y^{\prime}=a+b X
$$

\section{Keteragan :}

$Y^{\prime}$ : Nilai yang diprediksikan

a : Konstanta atau bila harga $\mathrm{X}: 0$

b : Koefisien regresi

$X$ : Nilai variabel independen

\section{HASIL PENELITIAN DAN}

PEMBAHASAN

\section{HASIL PENELITIAN}

\section{Uji Normalitas}

Uji Normalitas bertujuan untuk menguji apakah model regresi Variabel terikat (independen) dan Variabel (dependen) keduanya berdistribusi normal atau tidak.
Cara yang bisa ditempuh untuk menguji kenormalan data adalah dengan menggunakan uji normalitas Kolmogorov Smirnov nilai signifikansi > 0,05, maka data berdistribusi normal. Jika grafik Normal p-lot dengan melihat penyebaran dalamnya, apabila grafik tersebut penyebaran datanya mengikuti pola garis lurus , maka datanya normal . apabila uji Normalitas dalam Penelitian ini adalah sebagai berikut :

\section{One-Sample Kolmogorov-Smirnov \\ Test}

Unstandar

dized

Residual

\begin{tabular}{ccr}
\hline \multicolumn{1}{|c}{$\mathrm{N}$} & & 72 \\
\hline Normal $^{\mathrm{a}}$ & Mean &, 0000000 \\
\cline { 2 - 3 } Parameters $^{\mathrm{a}, \mathrm{b}}$ & Std. & 3,171292 \\
& Deviation & 02 \\
\hline Most Extreme & Absolute &, 084 \\
\cline { 2 - 3 } Differences & Positive &, 065 \\
\cline { 2 - 3 } & Negative &,- 084 \\
\hline Test Statistic &, 084 \\
\hline Asymp. Sig. (2-tailed) &, $200^{\mathrm{c}, \mathrm{d}}$ \\
\hline
\end{tabular}

Berdasarkan hasil Output uji normalitas menggunakan aplikasi SPSS 24 pada gambar diatas, menunjukkan nilai Kolmogorov-Smirnov Signifikan pada 0.200. Nilai tersebut $>0,05$, Hal tersebut 
membuktikan bahwa data penelitian Berupa Tes.

\section{Uji Linieritas}

Uji Linieritas bertujuan untuk mengetahui keterhubungan atau keterkaitan yang signifikan antara variable satu dengan yang lainnya. Uji linieritas dilakukan dengan pengujian pada SPSS dengan Test For Linierity pada taraf signifikansi 0,05 Dua variabel dikatakan mempunyai Hubungan yang Linier bila signifikansi ( linierity ) Kurang dari 0,05.

\section{ANOVA Table}

Sig.

\begin{tabular}{cccc}
\hline IQ & Betwe & (Combine &, 000 \\
Prestasi & en & d) & \\
Belajar & Group & Linearity &, 000 \\
\cline { 3 - 4 } & s & Deviation &, 002 \\
& & from & \\
& & Linearity & \\
& \multicolumn{3}{c}{ Within Groups } \\
\end{tabular}

Dari tabel Outpu diatas, diperoleh nilai signifikansi $=0,000$ lebih kecil dari 0,05. Karena, nilai Signifikansi kurang dari 0,05, maka dapat disimpulkan bahwa antara Variabel Kecerdasan Intelektual dan Prestasi belajar siswa terdapat Hubungan Linier secara Signifikansi.

\section{Analisis Korelasi Product Moment}

Setelah yang telah dikemukakan pada Bab

I, Hipotesis yang diajukan menyatakan "Terdapat Hubungan antara Kecerdasan Intelektual ( $I Q$ ) dengan Prestasi Belajar Siswa Pada Mata Pelajaran pendidikan Kewarganegaraan". Untuk mengetahui Hubungan Kedua Variabel tersebut, maka

\section{Correlations}

Prestasi

IQ Belajar

\begin{tabular}{|c|c|c|c|}
\hline \multirow[t]{3}{*}{ IQ } & $\begin{array}{c}\text { Pearson } \\
\text { Correlation }\end{array}$ & 1 &, $716^{* *}$ \\
\hline & Sig. (2-tailed) & & , 000 \\
\hline & $\mathrm{N}$ & 72 & 72 \\
\hline \multirow{4}{*}{$\begin{array}{l}\text { Prestasi } \\
\text { Belajar }\end{array}$} & Pearson &, $716^{* *}$ & 1 \\
\hline & Correlation & & \\
\hline & Sig. (2-tailed) & ,000 & \\
\hline & $\mathrm{N}$ & 72 & 72 \\
\hline
\end{tabular}

Pengujian signifikansi didasarkan pada pendapat Riduwan (2015: 83) yaitu apabila nilai $\mathrm{r}$ hitung $\geq \mathrm{r}$ tabel, maka nilai $\mathrm{r}$ hitung dinyatakan signifikan. Sebalknya apabila nilai $\leq \mathrm{r}_{\text {tabel }}$. maka nilai $\mathrm{r}_{\text {hitung }}$ dinyatakan tidak signifikan. Atas dasar tersebut, nialai $\mathrm{r}_{\text {hitung }}$ yang diperoleh dengan rumus Product Moment sebesar 0,716. Hasil yang sama juga ditunjukkan dari perhitungan melalui 
SPSS 24.0 for window denaga nilai signifikansi 0,000 .

\section{Analisis Regresi Sederhana}

Analisis Regresi sederhana adalah Hubungan secara Linier antara suatu Variabel Independen (X) dengan variabel dependen (Y). Analisis ini untuk mengetahui arah hubungan antara Variabel.

\begin{tabular}{cc|c|c|c}
\multicolumn{5}{c}{ Model Summary $^{\mathbf{b}}$} \\
& & & & $\begin{array}{c}\text { Std. } \\
\text { Error of }\end{array}$ \\
& & & & $\begin{array}{c}\text { R } \\
\text { the }\end{array}$ \\
& & Adjuste & d R & Estimat \\
Mo & & Squa & d & e \\
del & R & re & Square & e \\
\hline 1 &, $716^{\mathrm{a}}$ &, 513 &, 506 & 3,19386 \\
\hline
\end{tabular}

Nilai $\mathrm{R}$ yang merupakan symbol dari Koefisien. Pada Tabel diatas nilai korelasi adalah 0,716. Nilai ini dapat diinterprestasikan bahwa Hubungan kedua variabel penelitian berada pada kategori sangat tinggi. Melalui tabel diatas juga diperoleh nilai R Square atau koefisien Determinasi (KD) yang menunjukkan seberapa bagus model regresi yang dibentuk oleh interaksi variabel bebas dan variabel terikat. Nilai KD yang diperoleh adalah $51,3 \%$ adapun besar $48,7 \%$ merupakan faktor-faktor lainnya yang tidak termasuk ke dalam data penelitian ini. Angka hasil perhitungan stastistik tersebut dapat diartikan bahwa variabel terikat Kecerdasan Intelektual memiliki pengaruh Konribusi sebesar $51,3 \%$ terhadap Variabel Prestasi Belajar Siswa.

\section{SIMPULAN}

Berdasarkan data yang didapat dan telah melalui proses analisis, maka peneliti menyimpulkan bahwa: Berikut :

Terdapat Hubungan signifikan antara Kecerdasan Intelektual dengan Prestasi Belajar siswa. Hasil vaiabel Kecerdasan Intelektual diterima sebesar 51,3\% .

Berdasarkan Nilai Koefisien korelasi sebesar 0,716.sedangkan Berdasarkan Nilai $\mathrm{t}$ hitung disimpulkan bahwa hipotesis yang menyatakan kecerdasan intelektual berhubungan dengan Prestasi Belajar diterima karena $\mathrm{t}_{\text {hitung }}>\mathrm{t}$ tabel yaitu 8,853> 1,667 dimana hubungan Variabel lainnya Sebesar $48,7 \%$.

\section{DAFTAR PUSTAKA}

Abin Syamsuddin Makmun. (2004). Psikologi Pendidikan. Bandung: PT Rosda Karya Remaja.

Arikunto. Suharsimi(2009). Prosedur Penelitian Suatu Pendekatan Praktik.Jakarta : PT.Rineka Cipta.

Azwar.S.(2010) Pengantar Psikologi Intelegensi.Yogyakarta: Pustaka Pelajar. 
Darmadi, Hamid. 2010. Pengantar Pendidikan Kewarganegaraan. Bandung: Alfabeta.

Dalyono. 2009. Psikologi Pendidikan. Jakarta : Rineka Cipta

Hendryadi dan Suryani.( 2015 ). Metode

Riset Kuantitatif teori dan aplikasi pada penelitian Bidang Manajemen dan Ekonomi

Islam.Edisi Pertama. Jakarta:

Prenamedia Group.

Riduwan, 2010. Skala Pengukuran

Variabel-Variabel Penelitian.

Bandung: Alfabeta.

Samsuri.(2011).Pendidikan Karakter

Warga Negara.Yogyakarta:

Diandra Pustaka Indonesia

Hetika. 2008. Buku Penuntun Membuat

Tesis, Skripsi, Disertasi, Makalah.

Bandung: Bumi Aksara.

Zubaedi,(2011). desain pendidikan karakter.Edisi Pertama.

Jakarta:kencana prenada media Group.

Syah, Muhibbin. (2008). Psikologi Belajar. Jakarta: PT. Raja Grafindo Persad
Marliani, Rosleny. 2016. Psikologi Umum. Bandung: CV Pustaka Setia.

Ngalim Purwanto.(2013). Psikologi Pendidikan. Bandung PT Remaja Rosdakarya.

Retno Ayu Pratiwi. (2011). Psikologi Remaja. Jakarta: Raja Grafindo Persada.

Ormrd, Jeanne. Ellis.(2008). Psikolgi Pendidikan; membantu siswa tumbuh dan Berkembang.Jakarta: Erlangga. 